\title{
READERS
Insight
}

Journal of Management Info (JMI)

ISSN:2313-3376

www.readersinsight.net/jmi

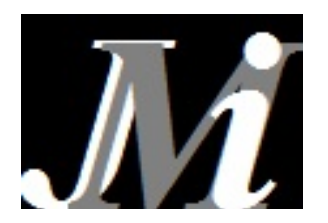

\section{Education and ICT facilities of Royal Belum Orang Asli school children}

\author{
Habibah @ Norehan Haron ${ }^{*}$, Hafizah Harun², Rudzidatul Akmam Dziyauddin ${ }^{1}$, and Azlina \\ Kamaruddin ${ }^{3}$
}

${ }^{1}$ Department of Engineering, UTM RAZAK School,Universiti Teknologi Malaysia,Jalan Semarak, 53100 Kuala Lumpur, Malaysia
${ }^{2}$ Sports Science Panel, Faculty of Education, Universiti Teknologi Malaysia, 81310 Johor, Malaysia
${ }^{3}$ Fakulti Komputeran, Universiti Teknologi Malaysia, 81310 Johor, Malaysia

*Corresponding author: habibahharon.kl@utm.my

\begin{abstract}
An effective teaching and learning methodology using Information and Communication Technology (ICT) is necessary to facilitate students to the easy access to a world of knowledge. The use of ICT essentially leads to significant impact on a conducive learning environment and also on the students' achievements. In Malaysia, the students come from different backgrounds and ethnics, which include Orang Asli. The urban students might face less difficulties in accepting the ICT in their lessons. A question is then raised regarding the readiness of the Orang Asli students, particularly in remote areas, like Royal Belum, Malaysia. This paper investigates the readiness of the primary students, namely from the Jahai group, in Royal Belum on the use of ICT devices, such as notepad and laptop. In addition to that, we studied the internet facilities and its connectivity at the schools, including some other related issues. Outcome of the observations showed positive readiness of Orang Asli students in using ICT devices. Nevertheless, a substantial effort from the ICT teachers seems crucial to the effective delivery of the ICT syllabus. Additionally, the schools suffer with slow connectivity as the data rate of $20 \mathrm{Mbps}$ needs to be shared with other nearby schools. This has affected the students' learning and also the teachers' daily tasks, for instance, in meeting District Education Department (PPD) requirements regarding uploading marks online. Therefore, it is appropriate for the government agencies to explore some initiatives in solving the current issues.
\end{abstract}

\section{ARTICLE INFORMATION}

\section{Received: 25 April 2015 \\ Revised: 25 May 2015 \\ Accepted: 25 June 2015}

DOI:

http://dx.doi.org//10.31580/jmi.v7i1.40

\section{Introduction}

Education is vital for the development of a nation and a country. Teaching and learning approaches vary from storytelling, classroom discussions, teacher or student-centred, training and research, in which the knowledge, skills, values and beliefs are transferred to the next generation. Education may be formal and informal, and include self-experiential learning[1].

"Experiential [learning] is a philosophy and methodology in which educators purposefully engage with students in direct experience and focused reflection in order to increase knowledge, develop skills, and clarify values"

(Association for Experiential Education, para. 2).

Based on a report by the National Institute of Multimedia Education [2] in Japan, when students are exposed to the educational Information and Communication Technology (ICT) via curriculum integration, it leads to a virtuous impact on the students' achievement. This can be explicitly seen in the context of knowledge, comprehension, practical skill as well as presentation skill across the subjects, like mathematics, science, and social study.In Malaysia, there is a policy named 'ICT in Education'[3] which governs, promotes and directs the use of ICT as an enabler to improve education and students' outcomes. Therefore, every school either in rural or urban areas is compulsory to have a computer lab to facilitate a quality and effective learning.

Previous studies [4]-[8] have shown that the use of ICT is able to enhance the teaching and learning at schools. Ahlan et.al [7] demonstrated that most of the Orang Asli students in Gombak, Selangor are familiar with computer and Internet at various levels of usage. This is due to the fact that this group of Orang Asli community lives in Selangor and can simply be exposed to the current technology. In a rural area of Kampar, Perak, Rugayah et. al [8] has found that only $5.2 \%$ of the Semai tribe was computer literate and $30.8 \%$ was illiterate [8].

Previous work are not focused to the case of Orang Asli in Royal Belum located in Perak, Malaysia. According to Nicholas [9], Orang Asli have diverse cultures, beliefs and also lifestyle, which indicate that they may have different behaviors related to education. This has drawn the authors' attention to investigate the readiness of children in remote areas, particularly the Orang Asli children on the use of ICT in their education. In order to fulfill the education agenda, well-equipped ICT facilities in the Orang Asli schools are necessary, thus, the assessment of the facility also become the focus of our study.

\section{Royal belum}

Due to the construction of Temenggor Dam and its completion in 1975, the Orang Asli were resettled in specific areas in Royal Belum, as depicted in Figure 1 [10]. The area of the reserved forest is about 290,000 hectares and more than 146,000 hectares of virgin forest [11]. The forest is divided into two sections: the upper Belum area, which stretches to the Thai-Malaysian border covering 117,500 hectares and the lower Belum mostly covered by Temenggor Lake [11]. 


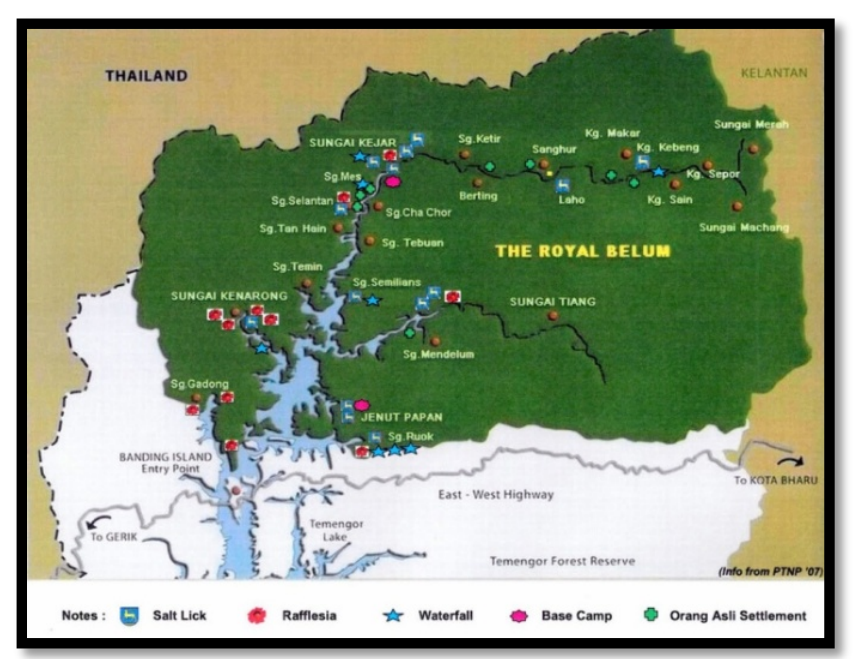

Fig. 1. Map of Royal Belum[10]

The Orang Asli ethnics in Malaysia can be broadly categorised into three: (i) Senoi, (ii) Negrito, and (iii) Protomalay [9]. Each ethnic can be divided into six sub-ethnics, which yields eighteen sub-ethnics in total. Each tribes can be further divided into six ethnic subgroups, which yields eighteen subgroups in total. Senoi is the largest ethnic group approximately $55 \%$, and this is followed by Proto Malays and Negritos at $42 \%$ and 3\% respectively [9]. The Department of Orang Asli Affair (JAKOA) is responsible to manage and monitor the Orang Asli welfare [6].

Royal Belum is predominantly inhabited by the Jaihai sub-ethnics from the Negrito group and minority from Temiar. Kamaruddin and Jusoh [6] highlighted that most of the Orang Asli settlements in Royal Belum maintain their nomadic forest-based lifestyles. However, the Sungai Tiang settlement is equipped with basic facilities, such as a primary school, a clinic, a community hall, wooden houses, and solar system for electricity.

\section{Research methodology}

In June 2014, a group of researchers from the Universiti Teknologi Malaysia (UTM) and collaborators from other universities in Malaysia conducted the Second Scientific Expedition at Royal Belum. The authors carried out a preliminary study at two schools in Royal Belum; Sekolah Kebangsaan Air Banun (SKAB) and Sekolah Kebangsaan Sungai Tiang (SKST).

Data collection was by qualitative method. Observations and interviews were carried out at both schools. Observations were done on students in the classroom at SKST. We observed their technology acceptance by focusing on their interactions with the devices and expressions towards the devices given, which were a laptop and a notepad. Meanwhile, in SKAB we observed the students during the ICT lessons conducted in the computer laboratory. Participants were twelve-year old were mostly Jaihai students who would be sitting the Year 6 National Examination (UPSR).

In addition to observations, interviews of the school principals as well as the teachers were conducted in identifying the issues or concerns related to the ICT facilities and education at the schools.

\section{Results and discussion}

\section{ICT Facilities}

Electricity is the primary component to ensure the ICT facilities work accordingly. In Royal Belum, the orang Asli community relies on solar panel as the source of electricity, particularly during the nights. We observed that every house must have at least one solar panel, however, the school consists of several solar panels in which every classroom or office was connected to their respective solar panel.

Figure 2 shows the solar panel connection to a Year 6 classroom. Since high power consumption is desired at every Orang Asli school, a hybrid technology is used to supply the electricity in facilitating a condusive environment for the students. Although there is hybrid technology, SKST still have a power trip problem that consequently makes the school's operation inefficient. Due to this and the limited available space in the school, SKST is unable to set-up a proper computer laboratory. This has affected the students learning the ICT subject. However, this is not the case for SKAB whereby a condusive computer room with new version of computers was properly set-up, as shown in Figure 3.

Since the schools are in the rural area which has hilly terrain, the coverage of optical fiber or the cellular networks is certainly a constraint. Because of this, Very Small Apperture Terminal (VSAT) is installed as a transmission medium to transmit and receive data, specifically for the internet connectivity, as depicted in Figure 4.

The VSAT can support up to $20 \mathrm{Mbps}$ to be shared with other nearby schools. This results to a low data rate or slow connectivity for the students or teachers to use the Internet connection, and the schools often have an intermittent network problem. Ultimately the students' lesson will be interrupted, although such school as SKAB do provide a good computer laboratory facilities. In addition, the teachers' tasks on any online activities, such as uploading students' assessment marks to the Ministry of Education website is also a stressful problem.

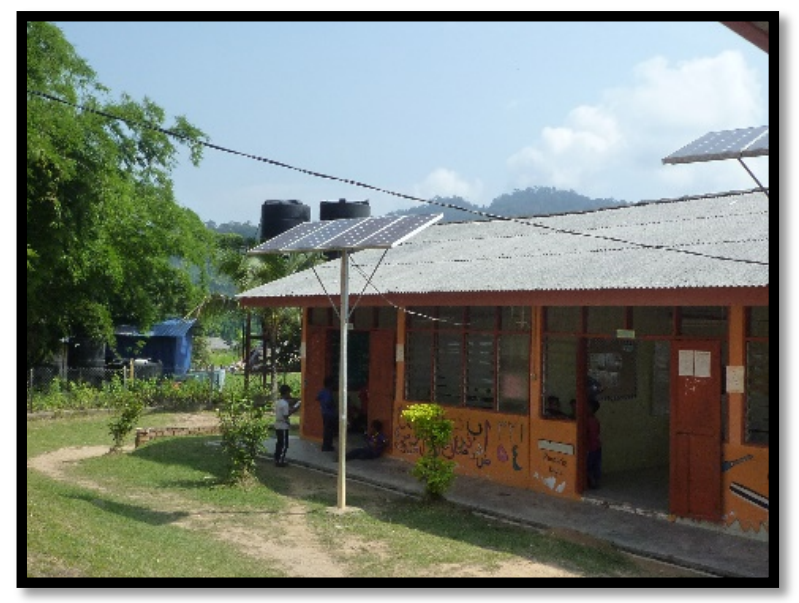

Fig. 2. Solar Panel as the main source of electricity

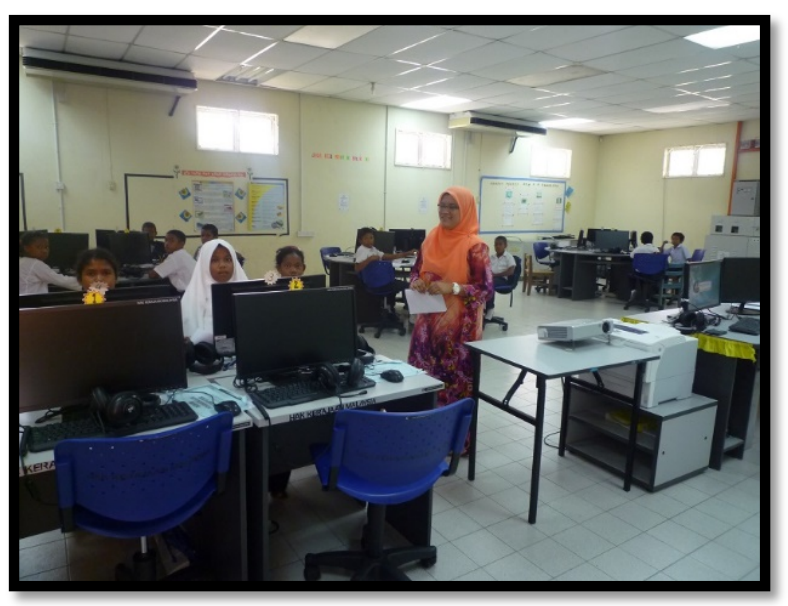

Fig. 3. Computer lab in Sekolah Kebangsaan Air Banun (SKAB) 


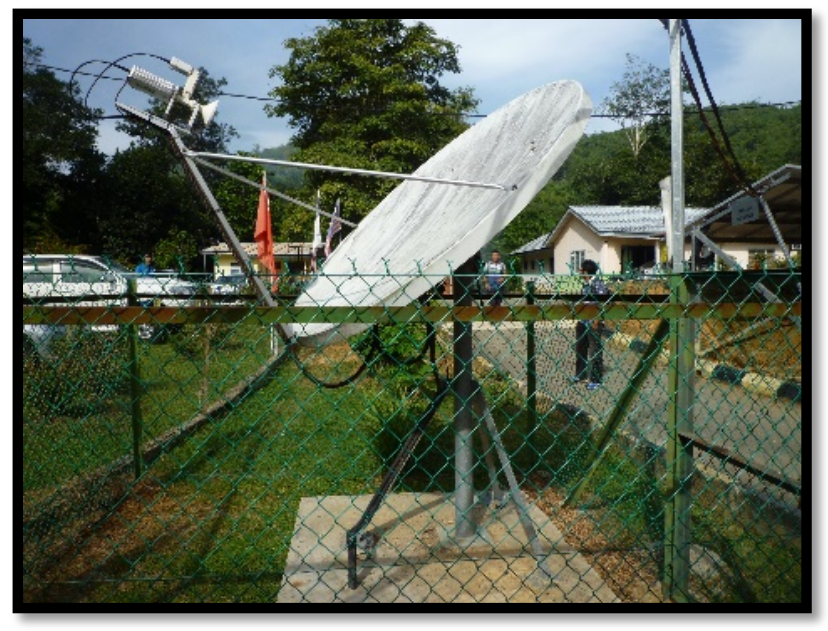

Fig. 4. VSAT is used as a transmitter and receiver for the internet connectivity

\section{ICT Education and interest}

Figures 5 and 6 show the Year 6 students at SKST interacting with the notepad. We observed that the students are impressed and the boys seem familiar with the devices, including the laptop, as can be depicted in Figure 7 . They were naturally scrolling their fingers to the media player icon to search for any music or video instead of the Microsoft office word icon. It was also observed that the session encourages the student to be more interactive, whereby they began to communicate with each other using their native language while playing with the notepad or laptop.

Although SKST does not have a proper computer laboratory, the teachers have informally taught the students the use of ICT. SKST provides accomodation for the teachers in the school compound. This makes it easier for the teachers to interact with the students after school hours, giving the potential students extra classes to prepare them for UPSR. Consequently, this has helped built a strong bonding between the teachers and the Orang Asli students, and even with their parents.

Meanwhile, from the observations on the students and interviews with the teachers at SKAB, the following were identified:

Orang Asli children are interested in learning ICT in the computer laboratory.

The key challenge for the teachers is to have to teach the children on the low level skills, such as how to use the basic components of the computer, like the mouse and keypad.

The current ICT syllabus is considered as high level for these Orang Asli children, thus, the completion of the syllabus is delayed. The delay is also caused by the need-to-teach the low level skills.

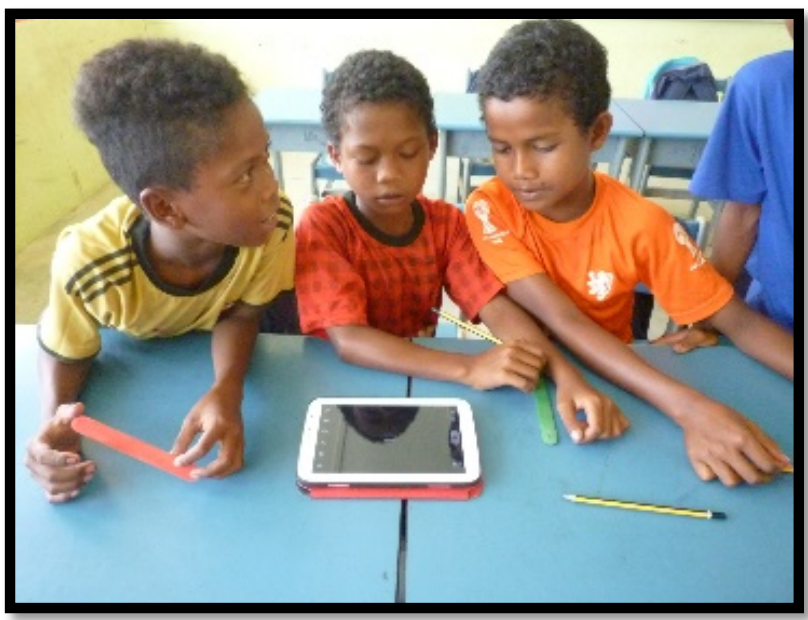

Fig. 5. Year 6 students were playing with the notepad

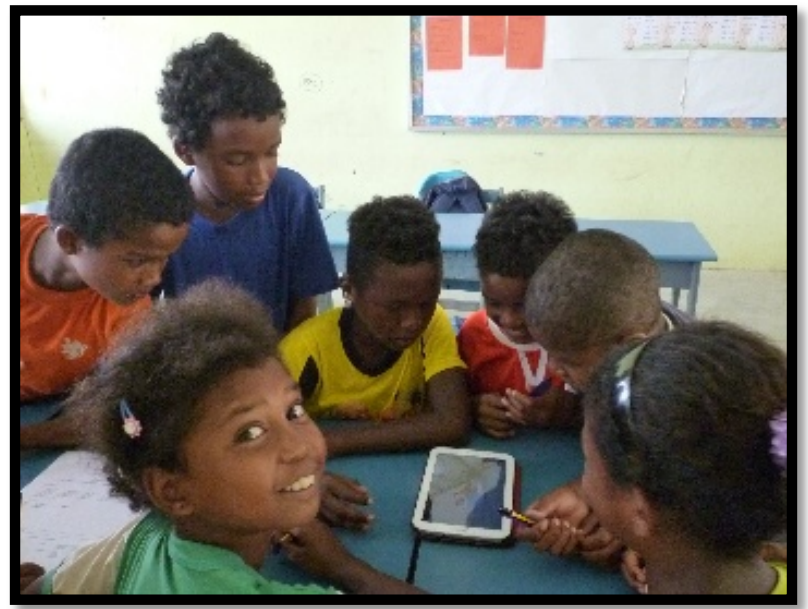

Fig. 6. The student were impressed with the notepad

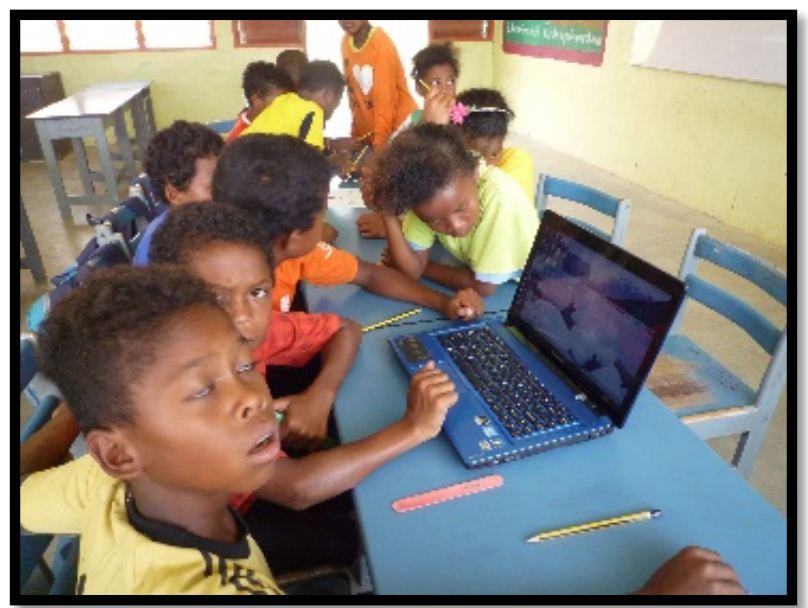

Fig. 7. The laptop also managed to capture the students' interest

\section{Conclusion}

Results have shown that the Jaihai students in SKAB are enthusiastic and ready to use the ICT devices that facilitate their learning. Meanwhile, the remote location of SKST contributes to the problems in setting up a proper computer lab. There is limited space, slow connectivity speed and insufficient power supply using hybrid solar. This somehow interrupted the students' lessons and also in the 
teachers' activities. The students had shown a considerable interest on the ICT devices, such as notepad and laptop. Apart from that, the students were prompted to communicate amongst themselves after the distribution of the devices. This was not observed during the beginning question and answer session. Nevertheless, they seem to be more inclined to use the devices to search for entertainment rather than educational functions. This paper concludes that the Jaihai students in primary schools are ready to use ICT in facilitating their studies. However, the ICT facilities have an issue in terms of slow connectivity in which the $20 \mathrm{Mbps}$ has to be shared with the nearby schools. Therefore, the government agencies must play a role in solving this important issue and support facilitation of learning especially in the rural areas and specifically the orang asli communiies in Royal Belum.

\section{Acknowledgment}

The authors would like to extend their gratitude to UniversitiTeknologi Malaysia for its flagship grant. Also, thank you to the Royal Belum Orang Asli community and the Minister of Perak State for their continuous support to the Scientific Expeditions.

\section{References}

“Association for experential education." [Online]. Available: http://www.aee.org/jee. [Accessed: 06-May-2015].

T. Sakamoto, "Trends and Issues of e-learning in Japan."

Malaysia National ICT Initiative, "Policy on ICT in Education Malaysia." Frost \& Sullivan, 2010

T. Chupil and J. Joseph, "Creating Knowledge For Change: A Case Study of SinuiPaiNanekSengik's Educational Work with Orang Asli Communities in Malaysia," 2003.
D. N. A. Hayes, "ICT and learning: Lessons from Australian classrooms," Comput. Educ., vol. 49, no. 2, pp. 385-395, Sep. 2007.

K. Kamaruddin and O. Jusoh, "Educational Policy and Opportunities of Orang Asli: A Study on Indigenious People in Malaysia," J. Hum. Resour. Adult Learn., vol. 4, 2008.

Ahlan,A.R.; Arshad,Y. (2011).The ICT social inclusion among orang asli com munity in Gombak area. International Conference on Research and Innovation in Information Systems (ICRIIS).

Rugayah Hashim, Kartika Sari Idris, YusAznitaUstadi, Farah Murni Merican and Sharifah F. S. M. Fuzi (2011). Digital Inclusion and Lifestyle Transformation among the Orang Asli:Sacrificing Culture for Modernity? Asian Social Science. 8(12). 80-87.

C. Nicholas, "Integration and Modernization of the Orang Asli: The impact on culture and identity," presented at the International Conference on the Indigenous People, Kuala Lumpur, 2005.

"Wonderful Malaysia | Travel Guide to the beautiful country of Malaysia." [Online]. Available: http://www.wonderfulmalaysia.com/. [Accessed: 05-May-2015].

"Royal Belum Nature Park, State, Birding Hornbill Migration, Tiger, Raflesia, Leeches, MNS, Perak, Malaysia, Thailand Border, Wildlife." [Online]. Available: $\quad$ http://www.endemicguides.com/RoyerBelumFR.htm. [Accessed: 06-May-2015]. 